\title{
Reviewer Acknowledgment 2021
}

\author{
Klaus Hausegger ${ }^{1}$
}

Springer Science+Business Media, LLC, part of Springer Nature and the Cardiovascular and Interventional Radiological Society of Europe (CIRSE) 2022

CardioVascular and Interventional Radiology (CVIR) would like to gratefully express acknowledgment and appreciation to all of our reviewers for contributing to the success of the journal last year. In 2021, more than 500 reviewers from 52 different countries performed more than 1100 reviews. They supported CVIR Editors with their valuable time and efforts, by carefully assessing manuscripts and writing review comments. Thank you for contributing to our endeavour to maintain our high scientific standards and congratulations on a job well done!

The General Data Protection Regulation (GDPR) legislation prevents us from publishing the names of reviewers. Nevertheless, we are indebted to all experts who have provided in-depth reviews of manuscripts submitted for publication in CVIR within the past year.

If you wish to receive a peer-reviewed certificate, please contact the CVIR Editorial Office at info@cvironline.org. It would be an honour to formally acknowledge your invaluable contribution to our esteemed journal!
Klaus A. Hausegger, MD.

Editor-in-Chief CVIR.

On behalf of all CVIR Editors.

Funding None.

\section{Declarations}

Conflict of interest None.

Consent for Publication For this type of study, consent for publication is not required.

Ethical Approval Not applicable.

Informed Consent Not applicable.

Publisher's Note Springer Nature remains neutral with regard to jurisdictional claims in published maps and institutional affiliations.

Klaus Hausegger

CVIR.Hausegger@kabeg.at

1 Department of Diagnostic and Interventional Radiology, Klagenfurt State Hospital, Klagenfurt, Austria 